\title{
Design and Fabrication of Novel Sheet-like Iron Vanadate Photocatalyst for the Photoreduction of Chromium
}

\author{
J. Vinoth Kumar, K. Leeladevi, M. Arunpandian, E.R. Nagarajan
}

\begin{abstract}
In past days, the occurrence of toxic heavy metal ions into the water and soil environment causes major health risk to the living organisms. In this work, we mainly focused on the photoreduction of hexavalent chromium $\left(\mathrm{Cr}^{6+}\right)$ using novel sheet-like $\mathrm{Fe}_{2} \mathrm{~V}_{4} \mathrm{O}_{13}$ photocatalyst under visible light irradiation. The sheet-like $\mathrm{Fe}_{2} \mathrm{~V}_{4} \mathrm{O}_{13}$ was tailored through hydrothermal process using ferric chloride and sodium metavanadate precursors without addition of any templates. The surface morphology, elemental analysis and various physical properties are characterized by numerous spectroscopic techniques. Interestingly, the sheet-like $\mathrm{Fe}_{2} \mathrm{~V}_{4} \mathrm{O}_{13}$ demonstrated proficient photocatalytic performances towards the reduction of $\mathrm{Cr}^{6+}$ into $\mathrm{Cr}^{3+}$. The obtained $U V$-visible spectroscopy results portrayed that sheet-like $\mathrm{Fe}_{2} \mathrm{~V}_{4} \mathrm{O}_{13}$ could reduce above of $\mathrm{Cr}^{6+}$ solution within 40 min. Moreover, the sheet-like $\mathrm{Fe}_{2} \mathrm{~V}_{4} \mathrm{O}_{13}$ holds very good stability even after five consecutive cycles. This study could open new insights for the design novel nanostructured binary metal oxides for environmental applications.
\end{abstract}

Keywords: Heavy metals, Photocatalyst, $\mathrm{Fe}_{2} \mathrm{~V}_{4} \mathrm{O}_{13}$, photoreduction, Chromium.

\section{INTRODUCTION}

Nowadays, with the rapid development of urbanization and industrialization progress has brought life-threatening water pollution, which induces diseases and deaths into the world. In particular, the contamination of toxic heavy metal ions into the environment increasing day-to-day, owing to their technical grandness. Among them, Hexavalent chromium $\left(\mathrm{Cr}^{6+}\right)$ is most dangerous metal which released through in electroplating, wood preservation, chrome plating, water-cooling towers, sanitary landfill leaching, steel manufacturing industries and so forth $[1,2]$. The release of chromium into the aquatic environment can causes carcinogenic, dermatitis, chronic ulcers, damages in gastrointestinal tract, kidney and lungs [3,4].

Revised Manuscript Received on December 09, 2019.

* Correspondence Author

E.R. Nagarajan*, Department of Chemistry, Nanomaterials Laboratory, International Research Centre, Kalasalingam Academy of Research and Education, Krishnankoil-626126, Tamil Nadu, India. Email: nagarajanklu@gmail.com.

J. Vinoth Kumar, Department of Chemistry, Nanomaterials Laboratory, International Research Centre, Kalasalingam Academy of Research and Education, Krishnankoil - 626126, Tamil Nadu, India. Email: vinothchem7@gmail.com

D. Sivaganesh, Department of Physics, International Research Centre, Kalasalingam Academy of Research and Education, Krishnankoil - 626126, Tamil Nadu, India. Email: ganesh.siva650@gmail.com

M. Arunpandian, Department of Chemistry, Nanomaterials Laboratory, International Research Centre, Kalasalingam Academy of Research and Education, Krishnankoil - 626126, Tamil Nadu, India. Email: arunpandiantt126@gmail.com
Therefore, World Health Organization (WHO) and U.S. Environmental Protection Agency strictly announced that $\mathrm{Cr}^{6+}$ maximum concentration into the drinking water is must below $0.05 \mathrm{mg} \mathrm{L}^{-1}[5,6]$. On the other hand, $\mathrm{Cr}^{3+}$ is an important element for maintaining the carbohydrate metabolism in human body, nutrient for diabetes and nucleic acid synthesis [7]. Therefore, exploitation of simple and green technique for reduction of $\mathrm{Cr}^{6+}$ into $\mathrm{Cr}^{3+}$ state is a necessary concern to the researchers. However, heterogeneous photocatalysis method is an eco-friendly method, high energy consumption, gigantic efficiency and low-cost technique for the degradation or reduction of organic pollutant into non-toxic compounds [8-12].

Recently, $\quad \mathrm{Fe}_{2} \mathrm{~V}_{4} \mathrm{O}_{13}$ materials has not yet been completely expanded or utilized in the field of photocatalysis and catalysis. Due to its magnetic behavior for easy recycle and high potential performances, $\mathrm{Fe}_{2} \mathrm{~V}_{4} \mathrm{O}_{13}$ is expected to be a superior material for the removal of hazardous heavy metal ions into the aquatic environment. Very few efforts have been made to examine lithium-ion batteries, Fenton-like catalyst, photocatalytic reduction $\mathrm{CO}_{2}$ and degradation gaseous isopropyl alcohol applications of $\mathrm{Fe}_{2} \mathrm{~V}_{4} \mathrm{O}_{13}$ nanomaterials [13-16]. The photocatalytic activity strongly depends on the crystalline nature, specific surface area and surface morphology [17]. Therefore, in order to meliorate their physicochemical properties of the photocatalyst, we must need to develop an efficient surface morphology with good crystallinity. To the best of our knowledge, for the first time, we report the sheet-like $\mathrm{Fe}_{2} \mathrm{~V}_{4} \mathrm{O}_{13}$ nanostructure for the degradation of toxic $\mathrm{Cr}^{6+}$ into the aquatic environment under visible light illumination.

In this regard, we tried an attempt for the synthesis of sheet-like $\quad \mathrm{Fe}_{2} \mathrm{~V}_{4} \mathrm{O}_{13}$ photocatalyst through simple hydrothermal route without the aid of any other templates. For the first time, the sheet-like $\mathrm{Fe}_{2} \mathrm{~V}_{4} \mathrm{O}_{13}$ were utilized as a visible light active photocatalyst for the reduction of $\mathrm{Cr}^{6+}$ into $\mathrm{Cr}^{3+}$. The result showed that the sheet-like $\mathrm{Fe}_{2} \mathrm{~V}_{4} \mathrm{O}_{13}$ is an superior photocatalyst for the reduction of carcinogenic $\mathrm{Cr}^{6+}$.

\section{EXPERIMENTAL SECTION}

\section{A. Materials}

Ferric chloride hexahydrate $\left(\mathrm{FeCl}_{3} \cdot 6 \mathrm{H}_{2} \mathrm{O}\right)$, sodium metavanadate $\left(\mathrm{Na}_{3} \mathrm{VO}_{4}\right)$, potassium dichromate $\left(\mathrm{K}_{2} \mathrm{Cr}_{2} \mathrm{O}_{7}\right)$ and all chemicals were of analytical grade used without further purification 


\section{B. Synthesis of sheet-like $\mathrm{Fe}_{2} \mathrm{~V}_{4} \mathrm{O}_{13}$}

In a typical procedure, $0.1 \mathrm{M} \mathrm{Na} \mathrm{VO}_{4}$ and $0.2 \mathrm{M}$ $\mathrm{FeCl}_{3} \cdot 6 \mathrm{H}_{2} \mathrm{O}$ were dissolved in $80 \mathrm{~mL}$ of de-ionized water under vigorous stirring for $1 \mathrm{~h}$. After that, the above suspensions were transferred into $100 \mathrm{~mL}$ Teflon-lined steel autoclave and kept $140{ }^{\circ} \mathrm{C}$ for $12 \mathrm{~h}$. Consequently, the autoclave was cooled down to the room temperature and the precipitate was collected, rinsed with water and alcohol for several times to remove impurities. Finally, the product was dried in an oven at $80^{\circ} \mathrm{C}$ for $12 \mathrm{~h}$. The overall synthesis procedure is illustrated in Scheme 1.

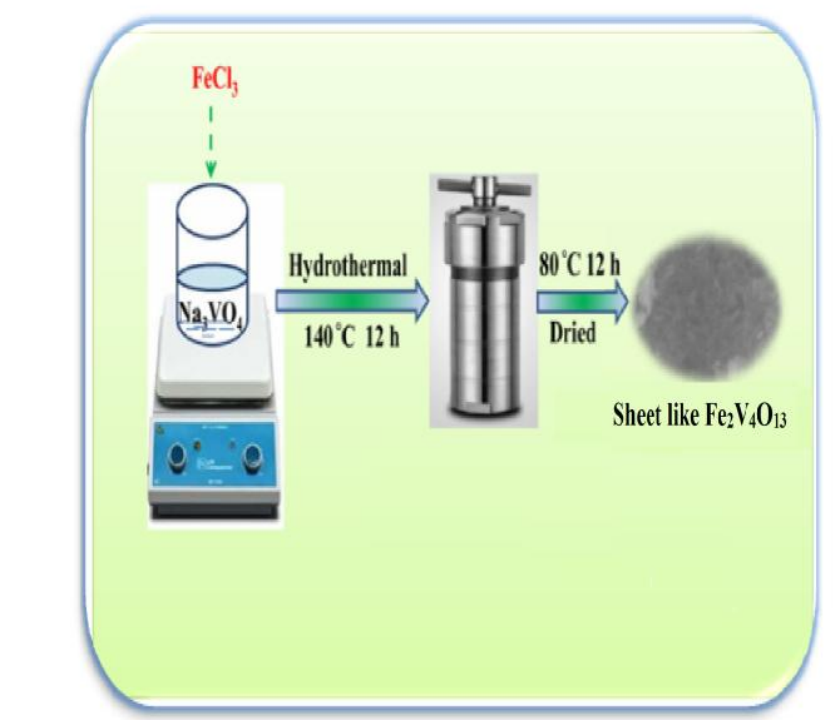

Scheme 1. Schematic representation for the fabrication of $\mathrm{Fe}_{2} \mathrm{~V}_{4} \mathrm{O}_{13}$ nanosheets.

\section{RESULT AND DISCUSSION}

X-ray diffraction (XRD) analysis was conducted to determine the crystalline phase and quality of the as-prepared material as shown in Fig. 1. The distinctive major diffraction peaks in the $2 \theta$ range at $12.41^{\circ}, 22.6^{\circ}, 23.82^{\circ}, 24.65^{\circ}$ and $26.71^{\circ}$ were correspond to the (002), (022), (210), (212) and (014) crystallographic planes of monoclinic phase of $\mathrm{Fe}_{2} \mathrm{~V}_{4} \mathrm{O}_{13}$, respectively and the results are well agreed to Standards JCPDS No [No. 87-1845]. There are no other impurity peaks such as $\mathrm{Fe}_{2} \mathrm{O}_{3}$ or $\mathrm{V}_{2} \mathrm{O}_{5}$ were detected, implied that the as-synthesized $\mathrm{Fe}_{2} \mathrm{~V}_{4} \mathrm{O}_{13}$ had high crystalline purity. The width of the high intense $\left(\begin{array}{lll}0 & 0 & 2\end{array}\right)$ peak was employed to calculate the mean crystalline size of the $\mathrm{Fe}_{2} \mathrm{~V}_{4} \mathrm{O}_{13}$ Scherer's formula as follows,

$$
X_{\mathrm{s}}=(k \lambda / \beta \cos \theta)
$$

Where $X s$ is the average grain size, $\lambda$ - wavelength of $\mathrm{X}$-ray, $\beta$ denoted as the Full width at half maximum of the peak, $\theta$ is diffraction angle and $k$ is constant. The calculated average size is to be $47 \mathrm{~nm}$.

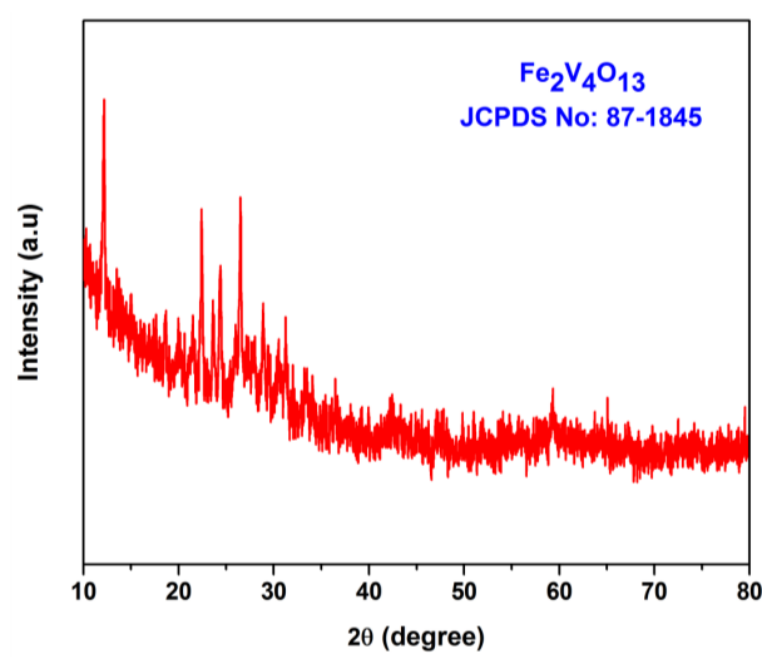

Fig. 1. XRD pattern of as-prepared sheet-like $\mathrm{Fe}_{2} \mathrm{~V}_{4} \mathrm{O}_{13}$.

Raman spectroscopy was used to investigate the bonding states of the as-prepared sheet-like $\mathrm{Fe}_{2} \mathrm{~V}_{4} \mathrm{O}_{13}$ and shown in Fig. 2. As from the Fig. 2, the Raman peaks below in the region of $450 \mathrm{~cm}^{-1}$ were correspond to the $\mathrm{O}-\mathrm{V}-\mathrm{O}$ twisting, rocking and $\delta-\mathrm{VO}_{2}$ vibrations. The peaks at 514 and $655 \mathrm{~cm}^{-1}$ were ascribed to the asymmetric and symmetric vibrations of V-O-V, respectively [18].

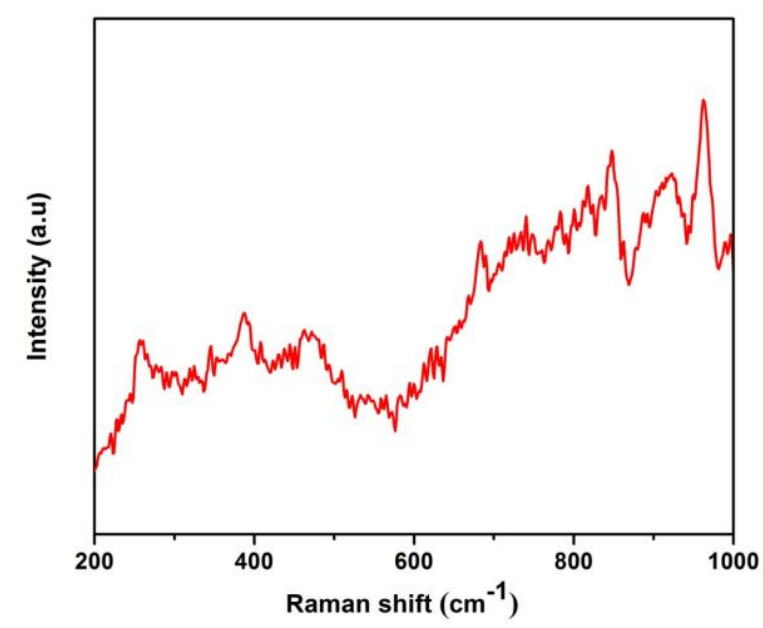

Fig. 2. Raman spectrum of $\mathrm{Fe}_{2} \mathrm{~V}_{4} \mathrm{O}_{13}$.

The surface topography of the as-synthesized $\mathrm{Fe}_{2} \mathrm{~V}_{4} \mathrm{O}_{13}$ was observed by SEM and TEM analysis. Fig. 3. (A\&B) shows the SEM images of $\mathrm{Fe}_{2} \mathrm{~V}_{4} \mathrm{O}_{13}$ which displays the well-defined 2D sheet-like structure with relatively smooth and fine surfaces. Furthermore, the TEM images in Fig. 3. (C\&D) clearly confirm the sheet-like structure of $\mathrm{Fe}_{2} \mathrm{~V}_{4} \mathrm{O}_{13}$ with average thickness of 50-60 nm. The elemental composition of as-prepared $\mathrm{Fe}_{2} \mathrm{~V}_{4} \mathrm{O}_{13}$ was determined by EDX analysis and shown in Fig. 4. The EDX results displayed the strong signals of $\mathrm{Fe}, \mathrm{V}$ and $\mathrm{O}$ elements which further confirm the successful formation of $\mathrm{Fe}_{2} \mathrm{~V}_{4} \mathrm{O}_{13}$ without impurities. 


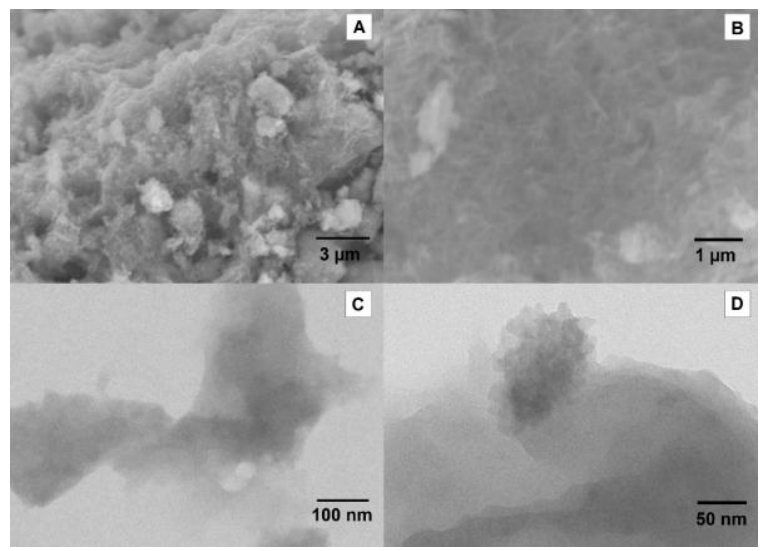

Fig. 3. (A\&B) SEM and (C\&D) TEM images of $\mathrm{Fe}_{2} \mathrm{~V}_{4} \mathrm{O}_{13}$.

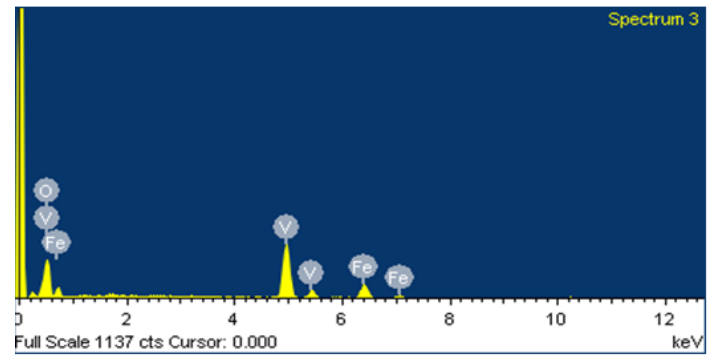

Fig. 4. EDX spectrum of $\mathrm{Fe}_{2} \mathrm{~V}_{4} \mathrm{O}_{13}$.

The optical property of as-prepared sheet-like $\mathrm{Fe}_{2} \mathrm{~V}_{4} \mathrm{O}_{13}$ was examined by UV-visible diffuse reflectance spectroscopy (DRS mode). Fig. 5A demonstrates the UV-visible diffuse reflectance spectra of the sheet-like $\mathrm{Fe}_{2} \mathrm{~V}_{4} \mathrm{O}_{13}$. It observed that the absorption edge was around to be $320 \mathrm{~nm}$ to $580 \mathrm{~nm}$. However, the energy gap value determined by Tauc's plot equation using DRS-UV spectrum. By integrating the liner region of Tauc's plot gives the band gap $2.78 \mathrm{eV}$ (Fig. 5B).
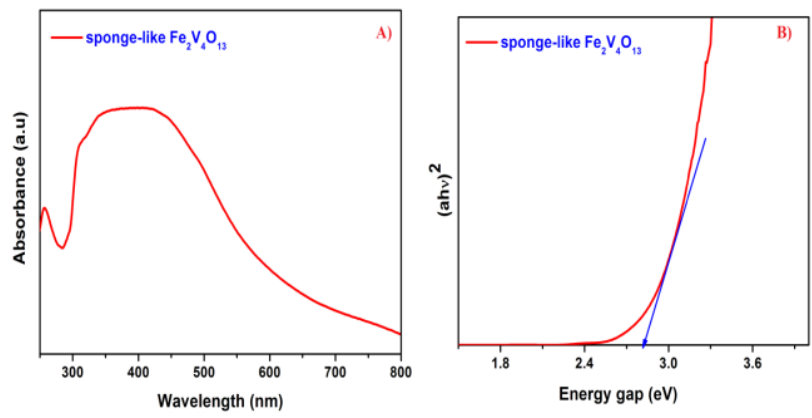

Fig. 5. (A) UV-Visible Diffuse reflectance and (B) Tauc's plot energy gap of spectrum of sheet-like $\mathrm{Fe}_{2} \mathrm{~V}_{4} \mathrm{O}_{13}$.

\section{A. Photocatalytic activity}

The photocatalytic removal of aqueous $\mathrm{Cr}^{6+}$ was performed under visible light in the presence of as-prepared sheet-like $\mathrm{Fe}_{2} \mathrm{~V}_{4} \mathrm{O}_{13}$ photocatalyst at various time intervals are given in Fig. 6. The photocatalytic activity of $\mathrm{Fe}_{2} \mathrm{~V}_{4} \mathrm{O}_{13}$ was executed under a UV-Visible spectrophotometer by scrutinizing the changes in the absorbance intensity of the reaction in the region between 300 to $500 \mathrm{~nm}$. There was no significant reduction was observed in the absence of $\mathrm{Fe}_{2} \mathrm{~V}_{4} \mathrm{O}_{13}$ catalyst (Fig. 7). The removal of $\mathrm{Cr}^{6+}$ was achieved by the presence of catalyst. The characteristic absorption peak is considerably reduced with increase in the time intervals. The reaction is regarded as complete when the absorption peak at $350 \mathrm{~nm}$ is vanishes. The entire reduction process of the $\mathrm{Cr}^{6}+$ was completed within $40 \mathrm{~min}$. The steady color change of the solution from yellow to colorless also proves that change in the oxidation state of chromium. These results confirm the complete reduction of $\mathrm{Cr}^{6+}$ by sheet-like $\mathrm{Fe}_{2} \mathrm{~V}_{4} \mathrm{O}_{13}$.

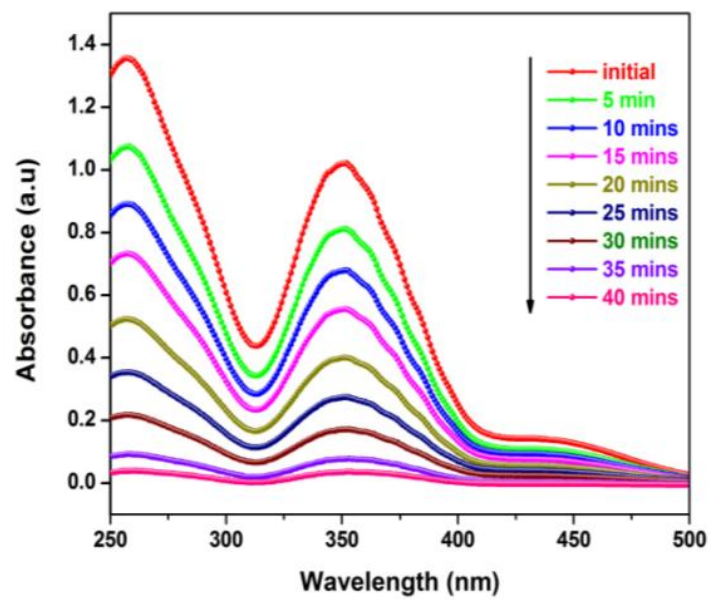

Fig. 6. Time-temporal UV-visible absorption spectra for the photoreduction of $\mathrm{Cr}^{6+}$ to $\mathrm{Cr}^{3+}$ in the presence of sheet-like $\mathrm{Fe}_{2} \mathrm{~V}_{4} \mathrm{O}_{13}$ under visible light irradiation.

\section{B. Effect of blank/photolysis and different catalyst on $\mathrm{Cr}^{6}+$ photoreduction}

The potential of $\mathrm{Fe}_{2} \mathrm{~V}_{4} \mathrm{O}_{13}$ catalyst was studied with different conditions and commercial photocatalyst under visible light conditions were shown in Fig. 7. It was shown that there was a slight changes or very negligible amount of reduction of $\mathrm{Cr}^{6+}$ takes place in the absence of light. Moreover, the photocatalytic activity obtained of well-known commercially available titanium dioxide $\left(\mathrm{TiO}_{2}\right)$ is only $39 \%$ whereas almost $98 \%$ of reduction was observed in the presence sheet-like $\mathrm{Fe}_{2} \mathrm{~V}_{4} \mathrm{O}_{13}$. It is importance to reveal that the $\mathrm{Fe}_{2} \mathrm{~V}_{4} \mathrm{O}_{13}$ showed excellent photocatalytic efficiency which might be due to the good crystalline and well-defined surface morphology.

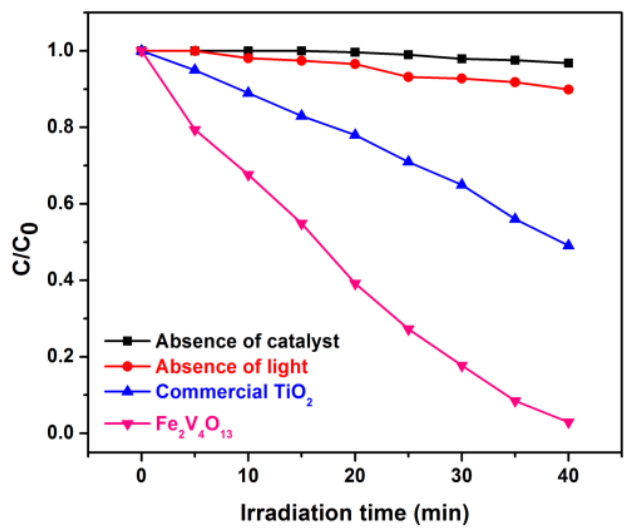

Fig. 7. Photoreduction of $\mathrm{Cr}^{6+}$ in the presence of different photocatalysts. 


\section{Reusability and stability}

The catalyst lifetime is another important parameter of the photocatalytic reaction in addition to the efficiency. For industrial applications, recycling of the photocatalyst is very essential to minimize the cost insinuation. In that way, the replication tests for the photoreduction of $\mathrm{Cr}^{6+}$ using sheet-like $\mathrm{Fe}_{2} \mathrm{~V}_{4} \mathrm{O}_{13}$ were performed and illustrated in Fig. 8. It revealed that the as-prepared $\mathrm{Fe}_{2} \mathrm{~V}_{4} \mathrm{O}_{13}$ shows excellent photoreduction efficiency towards $\mathrm{Cr}^{6+}$. The percentage of reduction of $\mathrm{Cr}^{6+}$ solution for five times of recycled photocatalysts is $98 \%, 97.3 \%, 95.1 \%, 93.2 \%$ and $91.4 \%$. The reduction of photocatalyst was showed after four cycle experiments. The result confirmed that the synthesized catalyst was most stable under visible light conditions. Only a small amount of catalyst vanished during the recycle process. This is due to adsorption of intermediate product which reduces the active surface of the photocatalyst. Moreover, the catalyst is easily recovered from the solution via centrifugation process. In our case, the as-synthesized sheet-like $\mathrm{Fe}_{2} \mathrm{~V}_{4} \mathrm{O}_{13}$ catalyst is extremely stable and efficient reusable capacities.

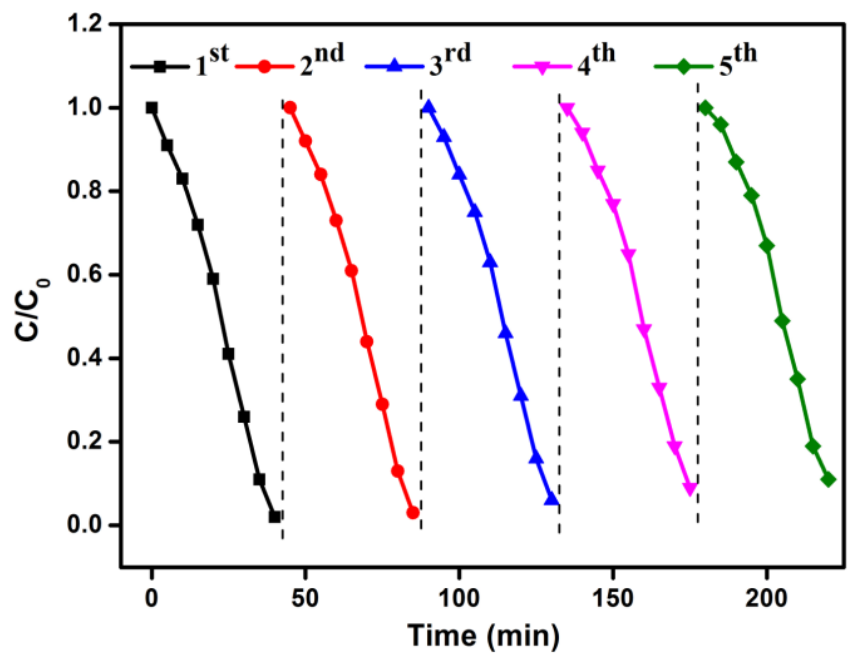

Fig. 8. Reusability efficiency of sheet-like $\mathrm{Fe}_{2} \mathrm{~V}_{4} \mathrm{O}_{13}$ for the photoreduction of $\mathrm{Cr}^{6+}$.

\section{CONCLUSION}

To sum up, we developed novel and efficient sheet-like $\mathrm{Fe}_{2} \mathrm{~V}_{4} \mathrm{O}_{13}$ photocatalyst via simple hydrothermal environment and characterized by numerous spectroscopic techniques such XRD, Raman, SEM, EDX, TEM and DRS-UV studies. The photocatalytic activity was tested against the reduction of carcinogenic $\mathrm{Cr}^{6+}$ under visible light irradiation. The results portrayed that the sheet-like $\mathrm{Fe}_{2} \mathrm{~V}_{4} \mathrm{O}_{13}$ could reduce above $98 \%$ when compared than commercial photocatalyst. The excellent performances may be ascribed to the large active surface area, good crystalline nature and well-defined 2D morphology which drastically promotes the mass transportation and diffusion of the $\mathrm{Cr}^{6+}$ and retards the photogenerated charge carriers. This present study demonstrated a new root for the environment remediation applications.

\section{ACKNOWLEDGMENT}

We are grateful to thank the Kalasalingam Academy of Research and Education, Tamil Nadu, India for providing research facilities.

\section{REFERENCES}

1. Y.C. Sharma, "Cr (VI) removal from industrial effluents by adsorption on an indigenous low cost material," Colloid Surf. A- Physicochem. Eng. Asp. 215 (2003) 155-162.

2. J. Xin, F. Zhang, Y. Gao, Y. Feng, S. Chen, A. Wu, A rapid colorimetric detection method of trace $\mathrm{Cr}$ (VI) based on the redox etching of $\mathrm{Ag}$ (core)-Au (shell) nanoparticles at room temperature, Talanta. 101 (2012) 122-127.

3. H. Zhang, Q. Liu, T. Wang, Z. Yun, G. Li, J. Liu, G. Jiang, "Facile preparation of glutathione- stabilized gold nanoclusters for selective determination of chromium (III) and Chromium (VI) in environmental water samples," Anal. Chim. Acta. 770 (2013) 140-146.

4. D. Basu, K. Blackburn, B. Harris, M. Neal, F. Stoss, "Health assessment document for chromium, Environmental Protection Agency," Springfield, VA. 1983.

5. X. Sun, L. Yang, Q. Li, J. Zhao, X. Li, X. Wang, H. Liu, "Amino-functionalized magnetic cellulose nanocomposite as adsorbent for removal of $\mathrm{Cr}$ (VI): synthesis and adsorption studies," Chem. Eng. J. 241 (2014) 175-183

6. R. A. Morello-Frosch, T. J. Woodruff, D. A. Axelrad, J. C. Caldwell, Air Toxics and Health Risks in California: The Public Health Implications of Outdoor Concentrations, Risk Analysis, 20 (2000) 273-292.

7. P.O. Brien, A. Kortenkamp, "The chemistry underlying chromate toxicity," Transition Met. Chem.20 (1995) 636.

8. I. Tang, J. Wang, G. Zeng, Y. Liu, Y. Deng, Y. Zhou, J. Tang, J. Wang, Z. Guo, "Enhanced photocatalytic degradation of norfloxacin in aqueous $\mathrm{Bi}_{2} \mathrm{WO}_{6}$ dispersions containing nonionic surfactant under visible light irradiation,” J. Hazard, Mater., 306 (2016) 295-304.

9. I. Ahmed, R. Bano, S. G. Musharraf, M. A. Sheraz, S. Ahmed, H. Tahir, Q. Arfeen, M. S. Bhatti, Z. Shad, S. F. Hussain, "Photodegradation of norfloxacin in aqueous and organic solvents: A kinetic study," J. Photochem. Photobiol.. A: Chemistry 302 (2015) 1-10.

10. R. Shahbazi, A. Payan, M. Fattahi, "Preparation, Evaluations and Operating Conditions Optimization of $\mathrm{Nano} \mathrm{TiO}_{2}$ over Graphene Based Materials as the Photocatalyst for degradation of Phenol," J. Photochem. Photobiol. A: Chemistry 364 (2018) 564-576.

11. J. V. Kumar, R. Karthik, Shen-Ming Chen, K. Natarajan, K. Chelladurai, C. C. Yang, V. Muthuraj, "3D Flower-Like Gadolinium Molybdate Catalyst for Efficient Detection and Degradation of Organophosphate Pesticide (Fenitrothion)," ACS Appl. Mater. Interfaces, 10 (2018) 15652-15664.

12. J.V. Kumar, R. Karthik, Shen-Ming Chen, V. Muthuraj, C. Karuppiah, "Fabrication of potato-like silver molybdate microstructures for photocatalytic degradation of chronic toxicity ciprofloxacin and highly selective electrochemical detection of $\mathrm{H}_{2} \mathrm{O}_{2}$," Sci. Rep., 6 (2017) 34149.

13. V. S. Nair, S. Sreejith, P. Borah, S. Hartung, N.Bucher, Y. Zhao, S. Madhavi, Crystalline $\mathrm{Li}_{3} \mathrm{~V}_{6} \mathrm{O}_{16}$ rods as high capacity anode material for aqueous rechargeable lithium batteries, RSC Adv. 4 (2014) 28601-28605

14. C. Mondal, A. K. Sasmal, S. M. Yusuf, M. D. Mukadam, J. Pal, M Ganguly, T. Pal, "Modified hydrothermal reaction for $\mathrm{CoV}_{2} \mathrm{O}_{6} \cdot 4 \mathrm{H}_{2} \mathrm{O}$ nanowire formation and the transformation and the transformation to $\mathrm{CoV}_{2} \mathrm{O}_{6} \cdot 2 \mathrm{H}_{2} \mathrm{O}$ single-crystals for antiferromagnetic ordering and spin-flop," RSC Adv. 4 (2014) 56977-56983.

15. P.P. Sahoo, B. Zoellner, P. A. Maggard, "Optical, Electronic and Photochemical properties of the type $\mathrm{Cu}_{3-\mathrm{X}} \mathrm{VO}_{4}$ Semiconductor," J. Mater. Chem. A 3 (2015) 4501-4509.

16. D. Sun, G. H. Jin, H. Y. Wang, P. Liu, Y. Ren, Y.F. Jiang, Y. G. Tang, X. B. Huang, "Aqueous rechargeable lithium batteries using $\mathrm{NaV}_{6} \mathrm{O}_{15}$ nanoflakes as high performance anodes," J. Mater. Chem. A. 2 (2014) 12999-13005.

17. H. Q. Song, Y. G. Liu, C. P. Zhang, C. F. Liu,G. Z. Cao, "Mo-doped $\mathrm{LiV}_{3} \mathrm{O}_{8}$ nanorod-assembled nanosheets as a high performance cathode material for lithium ion batteries," J. Mater. Chem. A. 3 (2015) 3547-3558.

18. R. Konta, H. Kato, H. Kobayashi, A. Kudo, "Photophysical properties and photocatalytic activities under visible light irradiation of silver vanadates," Phys. Chem. Chem. Phys. 5 (2003) 3061-3065. 


\section{AUTHORS PROFILE}

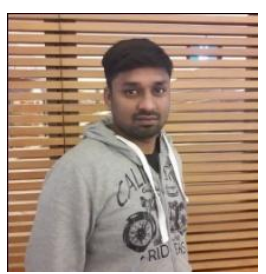

J. Vinoth Kumar is a Post-doctoral fellow at Kalasalingam Academy of Research and Education, Krishnankoil, India. He got his Ph.D Degree from Madurai Kamaraj University, Madurai, India. He is interested in synthesis of nanomaterials for photocatalysis and electrocatalysis applications.

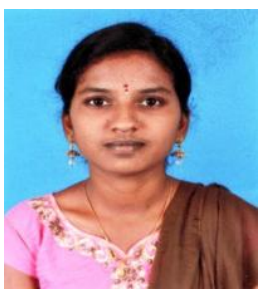

K. Leeladevi is a Ph.D student at Kalasalingam Academy of Research and Education, India. His research interest is synthesis of nanomaterials for photocatalysis applications.

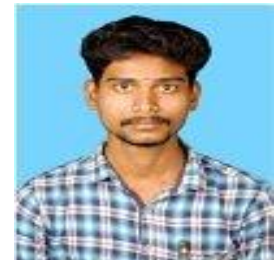

M. Arunpandian is a Ph.D student at Kalasalingam Academy of Research and Education, India. His research interest is in photocatalytic properties of rare earth attached metal oxides composite materials.

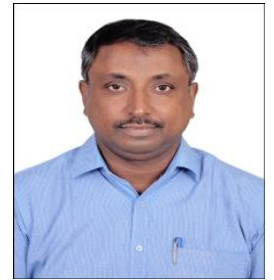

E.R. Nagarajan works as Associate Professor, Department of Chemistry, Kalasalingam Academy of Research and Education, Krishnankoil, Tamil Nadu, India. He received his $\mathrm{Ph} . \mathrm{D}$ degree at Anna University, Chennai, India. With a research in the applications of polymeric materials, co-ordination compounds, photocatalysis and electrochemical applications. 